DOI https://doi.org/10.30525/978-9934-588-47-1.15

\title{
ПРОЕКТ АВТОМОБІЛЬНОЇ СИСТЕМИ \\ ІЗ СИЛОВИМ ЗБУДЖЕННЯМ КОЛИВАНЬ У ТЕХНОЛОГІЧНІЙ ПЛАТФОРМІ
}

Петров Л. М., Осєнчінін М. Г.

\section{ВСТУП}

Характер поведінки конструкції автомобільних систем залежить від багатьох параметрів. Для спрощення моделі автомобільної системи провідні світові автомобільні виробники враховують тільки найбільш важливі особливості в конструкції щодо деформування несучих систем автомобілів. Наприклад, твердісні властивості визначаються деформаціями конструкції, що багато в чому залежать від його надійної експлуатації. Для одержання картини залежності переміщення й сили від часу можна використовувати моделі Максвелла й Кельвіна (рис. 1, 2), для більш удосконаленої експлуатації автомобільної системи може бути запропоновано модель згідно з рис. $3^{1}$.

Коефіцієнт пружності в цих моделях залежать від характеристик матеріалів і геометричних параметрів проектованої автомобільної системи. Завдяки цим моделям можна запропонувати конструктивні елементи, які створюють уповільнення і силовий вплив, що діють на автомобільну систему під час його розгону та руху.

Бернацкий В.В. Специализированный подвижной состав грузового автотранспорта: Учебное пособие для студентов вузов, обучающихся по специальности «Автомобиле- и тракторостроение» направления подготовки дипломированных специалистов «Транспортные машины и транспортнотехнологические комплексы». Москва : МГТУ «МАМИ», 2005. 48 с., с. 22-26.

Санкин Ю.Н. Частотный метод оценки курсовой устойчивости автомобиля на основе его моделей в виде систем с многими степенями свободы и нелинейным взаимодействием шин с дорожным покрытием / Ю. Н. Санкин, М. В. Гурьянов; под общ. ред. Ю. Н. Санкина. Ульяновск : УлГТУ, 2011. 243 с. C. $29-30$. 


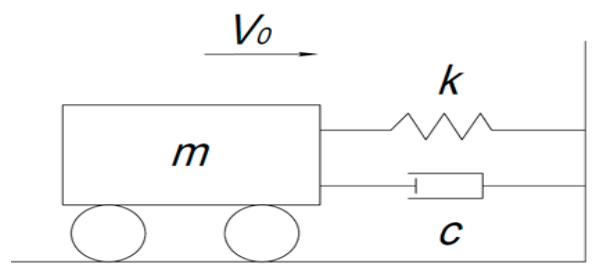

Рисунок 1. Модель Кельвіна*

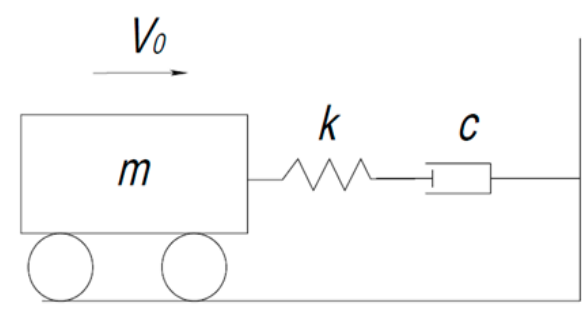

Рисунок 2. Модель Максвелла*

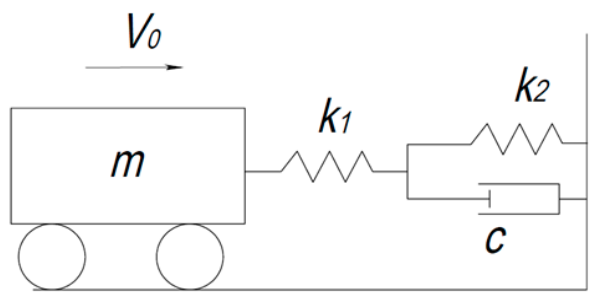

Рисунок 3. Змішана модель*

*де: $V_{0}$ - швидкість автомобіля; $m$ - маса автомобіля;

$k_{1}, k_{2}$ - коефіцієнти жорсткості; $C$ - коефіцієнт в 'язкості

Такі схематичні моделі можуть бути застосовані для первісної оптимізації конструкції автомобільної системи й зменшення ресурсномістких розрахунків методом в середовищі Excel, MatLab. Іншим підходом до аналітичного моделювання руху автомобільної системи є енергетичний, що заснований на передачі енергії у коливальному русі пружної системи, яка перетворюється на кінетичну енергію автомобільної системи під час технологічного роз'єднання несучої системи. Для розв'язання такої складної 
інженерної задачі можна використовувати комп'ютерні програми та спеціальні програми для розрахунків в середовищі Excel, при чому перевага віддавалася аналітичним методам розв'язання диференціальних рівнянь. Основні методи розрахунків складних процесів переміщення автомобільної системи подано в роботах Петрова Л. М. ${ }^{2}$

Застосовані розрахункові методи, які засновані на тому, що проводиться визначення картини деформації, потім отримані коефіцієнти використовують у розрахунках для подальшого проектування автомобільної системи.

Максимальна швидкість руху автомобільної системи становить близько 70 км/год, що зумовлено можливістю знехтувати процесом заносу за екстремальних умов іiі руху та зміщення рухомої платформи під час іiі пересування відносно несучої системи. Оскільки відсутнє дроселювання повітря у коливальній системі, а згідно 3 законом Джоуля-Томпсона навіть під час дроселювання повітря в пневморезонаторах температура не буде змінюватись. Отже, враховувати температурні режими, що виникають під час нагнітання повітря, недоцільно. При цьому отримана швидкість дасть змогу забезпечити максимальну акумуляцію рекуперованої енергії, що також зумовлене впровадженням управління пневмодинамічним поштовхом. Для регулювання початкового ступеня зарядки балонів-ресивера, який виконує функцію акумулятора, необхідно заряджати залежно від умов експлуатації. Враховуючи, що пневматична накопичувальна автомобільна система представляє собою не лише додатковий силовий рушій, а й також систему гальмування, клімат-контроль та систему охолодження в коливальній системі, то розрахунок раціональних параметрів коливальної системи та іiі маси необхідно проводити в комплексі, як єдине ціле. Отже, проведення аналізу динамічних навантажень ланок коливальної системи, системи в режимі переміщення автомобіля, складників резонаторного вузла, визначення закономірностей контактного тиску конструктивними параметрами елементів системи на технологічну платформу та удосконалення конструкції під'єднання технологічної платформи та несучої платформи 3 розгінним складником за допомогою

2 Петров Л.М. Теорія оптимізації якісних показників колісного рушія. Труды Одесского политехнического университета, 2010. Вып. 1(33)-2(34), c. 65-69. 
встановлення раціональних параметрів резонаторів рекуператорів несучої платформи, що дає можливість встановити тиск повітря, а тому й амплітуду резонаторів, під час їх роботи в режимі рекуперативного резонування за потрібною динамікою розгону автомобільної системи та визначення умов і способів підтримування динаміки руху автомобільної системи за відповідної динаміки зміни тиску в балоні-ресивері зі стисненим повітрям.

\section{1. Об'єкт досліджень}

Незалежно від конструкції підвіски технологічної платформи автомобільної системи будемо виходити 3 того, що кожна 3 пневморезонансних систем задана у вигляді певної функції

$$
F_{t}=F_{t}(\mathrm{t}) \text {, }
$$

де $\mathrm{t}=1,2, \ldots$, порядковий номер пневморезонатора.

Розглянемо простішу автомобільну систему, яка переміщується під дією примусової сили $\mathrm{F}(\mathrm{t})$. У любий момент часу на вантаж масою $\mathrm{m}$, який знаходиться на технологічній платформі, діє дві сили: сила пружності гнучкого елемента, яка пропорційна зміщенню технологічної платформи $\mathrm{X}$, та змушувальна сила $\mathrm{F}(\mathrm{t})$, яка змінюється у часі за законом, визначеним під'єднанням технологічної платформи до рами автомобільної системи (рис. 4, 5).

Для створеної автомобільної системи рівняння руху технологічної платформи 3 вантажем вагою $\mathrm{m}$ диференційне рівняння буде мати вигляд:

$$
\mathrm{m} \frac{d^{2} x}{d t^{2}}+\mathrm{cx}=F_{t}
$$

де $\mathrm{C}=\mathrm{H} / \mathrm{M}-$ жорсткість пружного елемента; $F_{t}-$ збуджуюча сила.

Поділивши обидві частини рівняння (1) на масу m, отримуємо рівняння руху автомобільної системи, яка запропонована згідно 3 рис. 4.

$$
\frac{d^{2} x}{d t^{2}}+\omega^{2} \mathrm{X}=\frac{F(t)}{m},
$$

${ }^{3}$ Шмидт Г. Параметрические колебания: Пер. с нем. Москва : Мир, 1978. 336 c. c $13-14$ 
де $\omega^{2}=\frac{c}{m}$

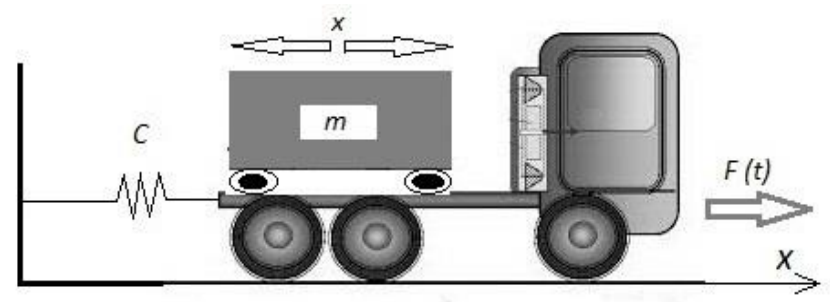

Рис. 4. Автомобільна система: С - жорсткість опорної поверхні; m - експлуатаційна маса; $\boldsymbol{x}$ - координата коливання

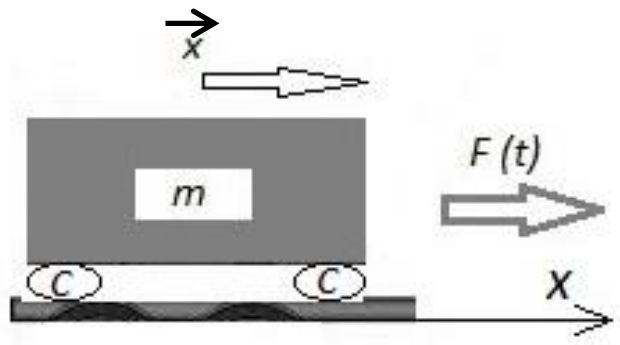

Рис. 5. Під'єднання технологічної платформи до автомобільної системи: $\mathbf{F}(\mathbf{t})$ - збуджуюча сила; $\mathbf{C}$ - жорсткість під'сднання технологічної платформи до рами автомобіля; m - маса технологічної платформи; $\vec{x}$ - напрямок руху технологічної платформи

Розглянемо рух автомобільної системи, коли вона відчуває поштовх, прикладений у момент часу $\mathrm{t}=\tau$, а дію постійно діючої сили $F_{t}$ приведемо до одиниці (рис. 6).

В запропонованому випадку рух автомобільної системи буде виконуватись згідно з рівнянням:

$$
\frac{d^{2} x}{d t^{2}}+\omega^{2} \mathrm{x}=\frac{1}{m}
$$


Рішення такого рівняння повинне задовольняти початковим умовам: $\mathrm{X}=0 ; \frac{d x}{d t}=0$, при $\mathrm{t}=\tau$, та повинно уявляти суму ${ }^{4}$ загального рішення відповідного однорідного рівняння:

$$
x_{1}=C_{1} \sin \omega \mathrm{t}+C_{2} \cos \omega \mathrm{t}
$$

Та приватного (окремого) рішення заданого рівняння

$$
x_{2}=\frac{1}{m \omega^{2}}=\frac{1}{C}
$$

Загальний вигляд

$$
\mathrm{x}=x_{1}+x_{2}=C_{1} \sin \omega \mathrm{t}+C_{2} \cos \omega \mathrm{t}+\frac{1}{C}
$$

Використавши початкові умови, знаходимо постійні інтегрування С1 та С2

$$
\begin{aligned}
& C_{1}=-\frac{\sin \omega \mathrm{t}}{\mathrm{c}} ; \\
& C_{2}=-\frac{\cos \omega \mathrm{t}}{\mathrm{c}}
\end{aligned}
$$

Та тоді

$$
\mathrm{X}=\frac{1-\cos \omega(t-\tau)}{C}
$$

Остання формула буде визначати закон руху гнучкого елемента, який знаходиться під технологічною платформою (рис. 7). Максимальне значення зміщення х складає:

$$
x_{\max }=\frac{2}{c}
$$

Тобто вдвічі перевищує переміщення, яке викликане статичною дією змушувальної сили $\mathrm{F}=1$.

4 Л.Э. Эльсгольц Дифференциальные уравнения и вариационное исчисления. Москва : Книга по Требованию, 2012. 424 с. с 115-119. 

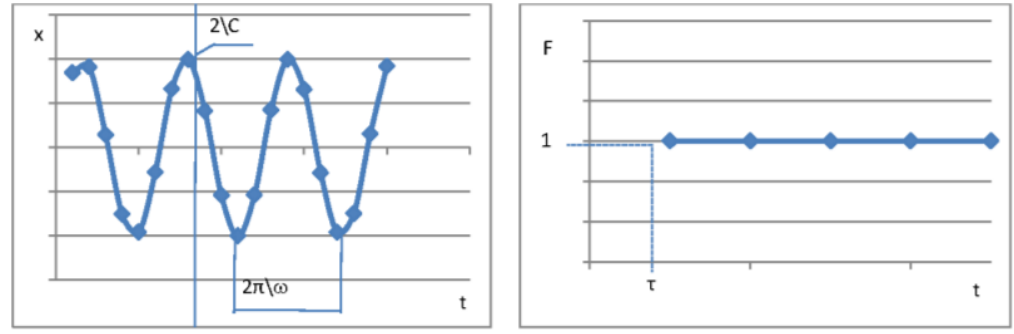

Рисунок 6. Залежність збуджуючої сили F та шляху від часу дії

Множення $C f(t)$ будемо сприймати як дію приведеної збуджуючої сили $\mathrm{F}(\mathrm{t})$, яка забезпечує рух автомобіля.

\section{2. Методи і алгоритми}

Розглянемо рух автомобільної системи, заподіяний пневморезонаторними пристроями. 3 цією метою в автомобільну систему резонаторні пристрої (пневморезонатори) (рис. 8) приймемо, що закон руху автомобільної системи підкоряється зміні деформації зчеплення енергетичного модуля 3 технологічним модулем у вигляді $f=f(t)$. Подовження гнучкого елемента у певний момент часу дорівнює $\mathrm{x}-f$. При цьому сила пружності пружного елемента буде дорівнювати: $\mathrm{C}(\mathrm{x}-f)$

Тоді диференційне рівняння руху автомобільної системи буде мати вигляд:

$$
\mathrm{m} \frac{d^{2} x}{d t^{2}}=\mathrm{C}(\mathrm{x}-f)=0
$$

Розділимо обидві частини рівняння на вагу технологічної платформи та отримуємо рівняння:

$$
\frac{d^{2} x}{d t^{2}}+\omega^{2} \mathrm{x}=\frac{C f(t)}{m}
$$

Рівнянню (4) відповідає схема руху автомобіля 3 рухомою технологічною платформою (рис. 7). 


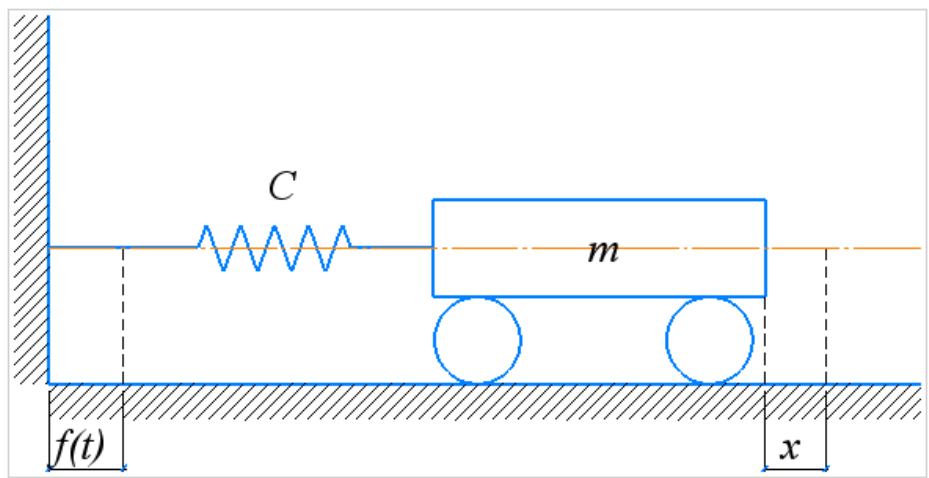

Рисунок 7. Схема автомобіля з рухомою технологічною платформою

Множення $C f(t)$ відносимо до дії приведеної вимушеної сили $\mathrm{F}(\mathrm{t})$, яка сприяє руху автомобільної системи.

\section{3. Рівняння руху автомобільної системи під дією збуджуючої сили}

Схема загального вигляду автомобільної системи 3 рухливою технологічною платформою показана на рис. 8.

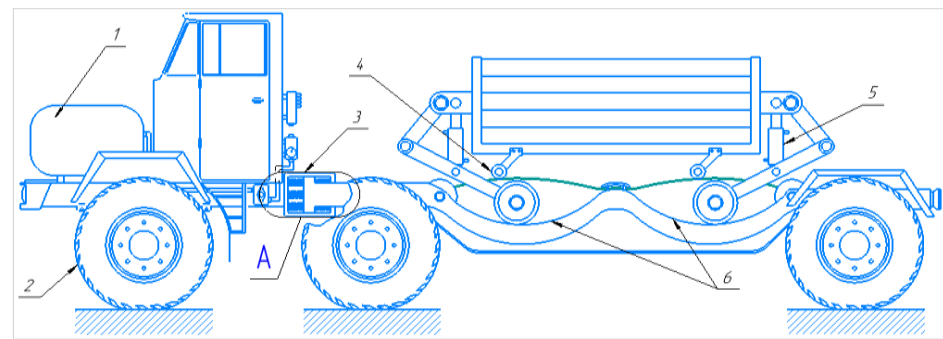

Рисунок 8. Схема загального вигляду автомобільної системи з рухливою технологічною платформою: 1 - балон-ресивер;

2 - опорні колеса; 3 - демпфер; 4 - важелі руху;

5 - пневморезонатори; 6 - несуча система

Метод варіації вільних постійних для визначення зміни збуджуючої сили. 
Часне рішення рівняння (2):

$$
\frac{d^{2} x}{d t^{2}}+\omega^{2} \mathrm{X}=\frac{F(t)}{m}
$$

має вигляд:

$$
x=C_{1} \sin \omega \mathrm{t}+C_{2} \cos \omega \mathrm{t}
$$

Приймемо, що величини С1 та С2 будуть не постійними, а змінними. В результаті визначення шляху переміщення автомобільної системи $\mathrm{x}(\mathrm{t})$ буде спрямовано на визначення двох функцій-постійних, які змінюються 3 часом: $\mathrm{C}_{1}(\mathrm{t})$ та $_{2}(\mathrm{t})^{5}$.

Продиференціюємо рівняння (4), в якому постійні $\mathrm{C} 1$ та $\mathrm{C} 2$ будуть змінними:

$$
\frac{d x}{d t}=C_{1} \omega \cos \omega \mathrm{t}-C_{2} \omega \sin \omega \mathrm{t}+\frac{d C_{1}}{d t} \sin \omega \mathrm{t}+\frac{d C_{2}}{d t} \cos \omega \mathrm{t}
$$

Приймемо, що складники $C_{1} \sin \omega \mathrm{t}+C_{2} \cos \omega \mathrm{t}$ не впливають на інтенсивність руху автомобільної системи, а тому

$$
\frac{d C_{1}}{d t} \sin \omega \mathrm{t}+\frac{d C_{2}}{d t} \cos \omega \mathrm{t}=0
$$

Рівняння для визначення швидкості руху автомобільної системи прийме вигляд:

$$
\frac{d x}{d t}=\mathrm{C}_{1} \omega \cos \omega \mathrm{t}-\mathrm{C}_{2} \omega \sin \omega \mathrm{t}
$$

Продиференціювавши рівняння (6), отримуємо рівняння щодо прискорення, з яким рухається автомобільна система:

$$
\frac{d^{2} x}{d t^{2}}=-\mathrm{C}_{1} \omega^{2} \sin \omega \mathrm{t}-\mathrm{C}_{2} \omega^{2} \cos \omega \mathrm{t}+\frac{d C_{1}}{d t} \omega \cos \omega \mathrm{t}-\frac{d C_{2}}{d t} \omega \sin \omega \mathrm{t}
$$

Підставимо у рівняння (3) рівняння (4) та (7) отримуємо рівняння зв’язку змінних постійних та збуджуючої сили, яка забезпечує переміщення автомобільної системи:

5 Андре Анго. Математика для электро- и радиоинженеров. Москва, 1965 г., 780 стр. с илл. С. 315-316 


$$
\frac{d C_{1}}{d t} \cos \omega \mathrm{t}-\frac{d C_{2}}{d t} \sin \omega \mathrm{t}=\frac{F(t)}{m \omega}
$$

Підставивши (5) та (8), заходимо похідні $\frac{d C_{1}}{d t} \mathrm{i} \frac{d C_{2}}{d t}$

$$
\begin{gathered}
\frac{d C_{1}}{d t}=\frac{F(t)}{m \omega} \cos \omega \mathrm{t} ; \\
\frac{d C_{2}}{d t}=-\frac{F(t)}{m \omega} \sin \omega \mathrm{t}
\end{gathered}
$$

Після інтегрування отримуємо систему коефіцієнтів С1 та С2

$$
\left\{\begin{array}{l}
C_{1}=\frac{1}{m \omega} \int_{0}^{t} F(\tau) \cos \omega \tau d \tau+B_{1} \\
C_{2}=-\frac{1}{m \omega} \int_{0}^{t} F(\tau) \cos \omega \tau d \tau+B_{2}
\end{array},\right.
$$

де $B_{1}$ та $B_{2}$ - коефіцієнти, які визначають координати зміщення технологічної платформи.

Після підстановки рівняння (9) у рівняння (4) отримуємо рівняння переміщення технологічної платформи:

$$
\begin{gathered}
x=\frac{1}{m \omega}\left[\sin \omega t \int_{0}^{t} F(\tau) \cos \omega \tau d \tau-\cos \omega t \int_{0}^{t} F(\tau) \sin \omega \tau d \tau\right]+ \\
+B_{1} \sin \omega \mathrm{t}+B_{2} \cos \omega \mathrm{t}
\end{gathered}
$$

Поєднуючи інтеграли в рівнянні (10), отримуємо спрощене рівняння переміщення автомобільної системи

$$
x=B_{1} \sin \omega t+B_{2} \cos \omega t+\frac{1}{m \omega} \int_{0}^{t} F(\tau) \sin \omega(t-\tau) d \tau
$$

3 рівняння (7) після диференціювання отримуємо рівняння швидкості, з якою може рухатись автомобільна система:

$$
\frac{d x}{d t}=B_{1} \omega \cos \omega \mathrm{t}-B_{2} \omega \sin \omega \mathrm{t}+\frac{1}{m} \int_{0}^{t} F(\tau) \cos \omega(t-\tau) d \tau
$$

Значення коефіцієнтів координат зміщення технологічної платформи знаходимо, коли призначимо графічні координати початку відліку руху автомобільної системи. Приймемо, що при $\mathrm{t}=0$ переміщення почалось $\mathrm{x}=0, x_{0}=V_{0}$. Тоді, згідно з рівняннями (10) та (12) отримуємо 


$$
\begin{aligned}
& B_{1}=\frac{V_{0}}{\omega} ; \\
& B_{2}=x_{0}
\end{aligned}
$$

Зі значенням набутих коефіцієнтів координат зміщення технологічної платформи знаходимо рух автомобільної системи:

$$
x=x_{0} \cos \omega t+\frac{V_{0}}{\omega} \sin \omega t+\frac{1}{m \omega} \int_{0}^{t} F(\tau) \sin \omega(t-\tau) d \tau
$$

У формулі складники, які не знаходяться під знаком інтеграла, визначають рух автомобільної системи на ії початку. Складник зі знаком інтеграла визначатиме дію збуджуючої сили $\mathrm{F}(\mathrm{t})$.

\section{4. Результати досліджень}

Результати досліджень впливу на рух автомобільної системи вихідних параметрів ( $\mathrm{t}$ - час, $\mathrm{C}$ - жорсткість пружного елемента, $\omega$ - колова частота, F - збуджуюча сила) представлені на графіках (рис. 9-14).

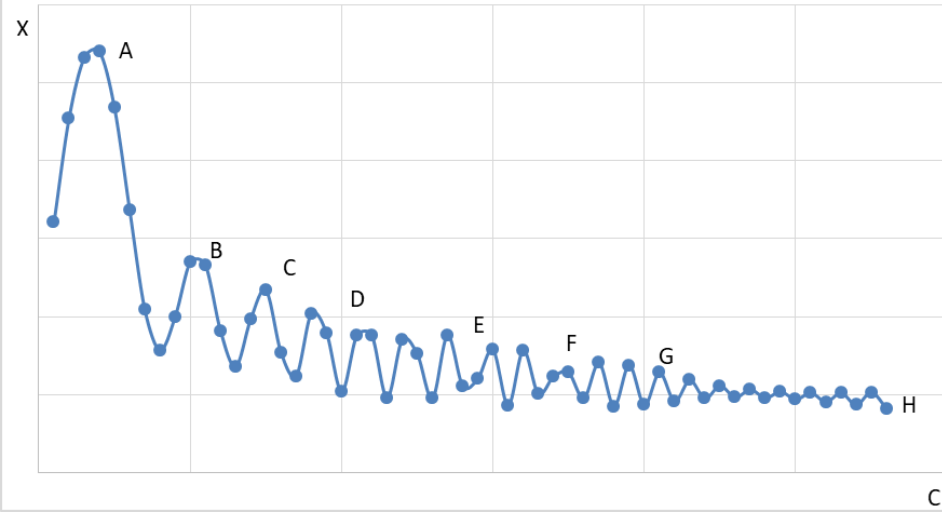

Рис. 9. Залежність переміщення автомобільної системи від жорсткості пружних елементів 


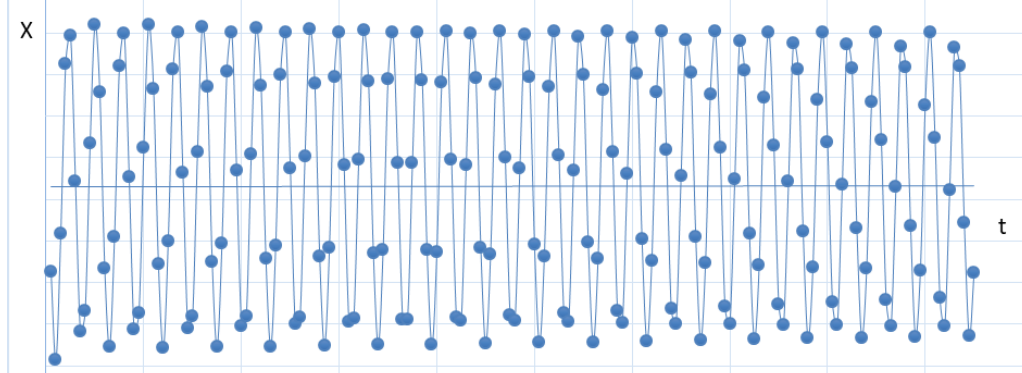

Рис. 10. Залежність переміщення автомобільної системи від часу

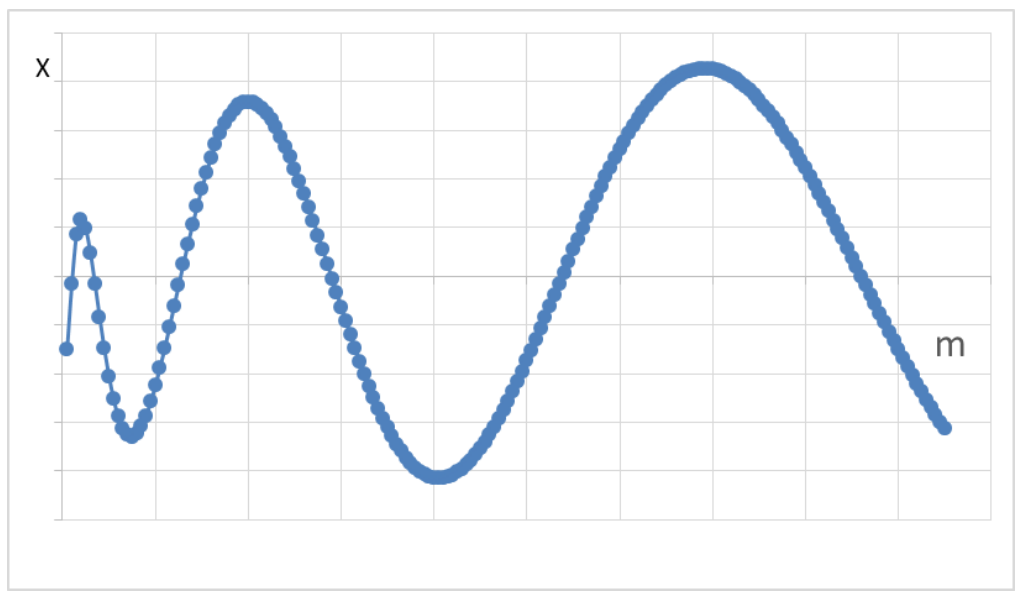

Рис. 11. Вплив експлуатаційної маси на коливання технологічної платформи з одночасним переміщенням автомобільної системи 


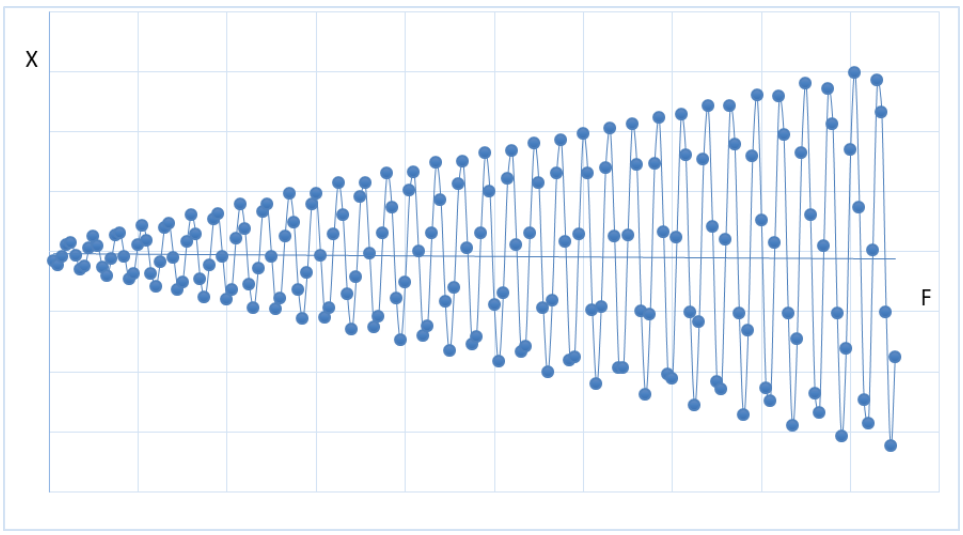

Рис. 12. Вплив збуджуючої сили на переміщення автомобільної системи

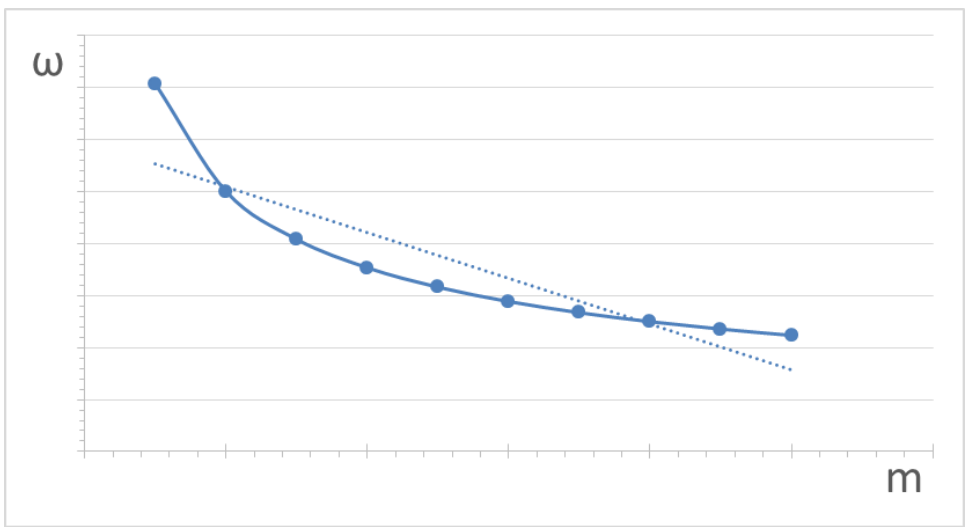

Рис. 13. Визначення оптимальної зони колової частоти від впливу на неї маси 


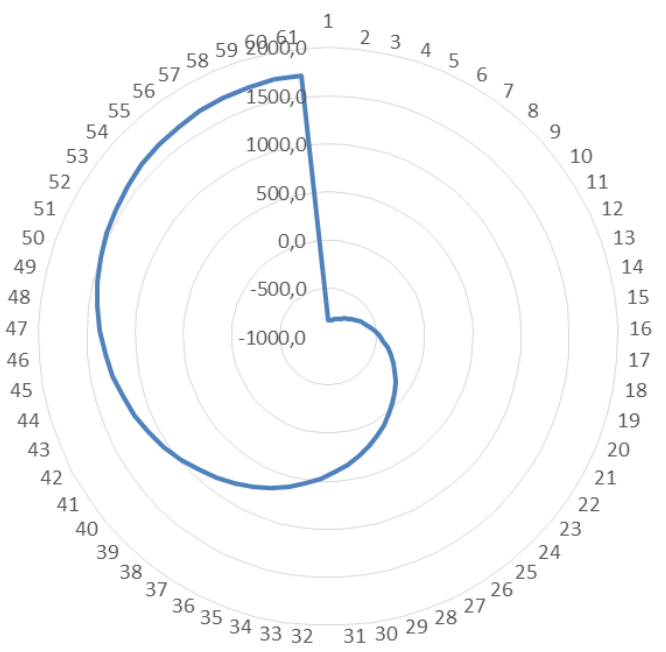

Рис. 14. Діаграма зони роботи пневморезонаторів

\section{ВИСНОВКИ}

1. Створено автотранспортну систему 3 динамічно-роз'єднаними експлуатаційними вагами.

2. Запропоновано теоретичну технологію «витягування» однієї ваги автотранспортної системи відносно другої та навпаки.

3. Розроблено математичну модель автотранспортної системи 3 взаємовитягуванням рухомих ваг одна відносно другої для відпрацювання руху цієї системи під дією пневморезонаторів 3 мінімальними витратами енергії.

\section{АНОТАЦІЯ}

У статті розглянуто можливість створення автотранспортної системи з динамічно роз'єднаними експлуатаційними вагами, які у процесі взаємного зміщення відпрацьовують силу збудження у напрямку руху, що дозволяе процес переміщення автотранспортного засобу перетворити на процес «витягування» однієї ваги відносно другої та навпаки. 3 цією метою технологічна платформа була рухомо під'єднана до загальної платформи за допомогою пневморезонаторів.

Розроблено математичну модель автотранспортної системи 3 взаємовитягуванням рухомих ваг одна відносно другої для відпрацювання руху цієї системи під дією пневморезонаторів 3 мінімальними витратами енергії. Результати розрахунків по 
отриманому диференційному рівнянню показали зону найбільш ефективної роботи пневморезонаторів.

Розглянуто можливість створення теоретичного макету автотранспортної системи з пневматичними резонаторами, рух якої забезпечує збуджуюча сила. Альтернативним джерелом енергії для силових установок автомобільних систем може бути використано стиснуте повітря, яке накопичене у пневморисевері, яка потім 3 пневморесивера використовується у пневморезонаторах як механічна енергія у перетворенні потенціальної енергії на кінетичну енергію руху технологічної платформи.

\section{ЛІТЕРАТУРА}

1. Бернацкий В. В. Специализированный подвижной состав грузового автотранспорта: Учебное пособие для студентов вузов, обучающихся по специальности «Автомобиле- и тракторостроение» направления подготовки дипломированных специалистов «Транспортные машины и транспортно-технологические комплексы». Москва : МГТУ «МАМИ», 2005. 48 с.

2. Андре Анго. Математика для электро- и радиоинженеров. Москва, 1965 г., 780 стр. с илл.

3. Петров Л.М., Теорія оптимізації якісних показників колісного рушія. Труды Одесского политехнического университета. 2010. Вып. 1(33)-2(34), с. 65-69.

4. Шмидт Г. Параметрические колебания: Пер. с нем. Москва : Мир, 1978. 336 с.

5. Санкин Ю.Н. Частотный метод оценки курсовой устойчивости автомобиля на основе его моделей в виде систем с многими степенями свободы и нелинейным взаимодействием шин с дорожным покрытием ; под общ. ред. Ю. Н. Санкина. Ульяновск : УлГТУ, 2011. 243 с.

6. Эльсгольц Л.Э. Дифференциальные уравнения и вариационное исчисления. Москва : Книга по Требованию, 2012. 424 с.

Information about authors: Petrov L. M., Candidate of Technical Sciences, Associate Professor, Military Academy Odessa city 21, First Station Str., Odessa, 65000, Ukraine

Osienchinin M. H., Bachelor, Commander of a Training Group

Military Academy Odessa city 10, Fountain road, Odessa, 65000, Ukraine 